Revista Universo Contábil, ISSN 1809-3337

FURB, v. 6, n.1, p. 28-45, jan./mar., 2010

doi:10.4270/ruc.2010102

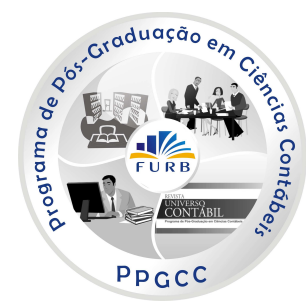

\title{
ESTRUTURA CURRICULAR DO CURSO DE CIÊNCIAS CONTÁBEIS NO BRASIL VERSUS ESTRUTURAS CURRICULARES PROPOSTAS POR ORGANISMOS INTERNACIONAIS: UMA ANÁLISE COMPARATIVA ${ }^{1}$
}

\section{STRUCTURE OF THE ACCOUNTANCY CURRICULUM IN BRAZIL VERSUS CURRICULAR STRUCTURES PROPOSED BY INTERNATIONAL AGENCIES: A COMPARATIVE ANALYSIS}

\author{
Ernani Ott \\ Doutor em Ciencias Economicas y Empresariales \\ pela Universidad de Deusto - España \\ Professor do Mestrado em Ciências Contábeis da \\ Universidade do Vale do Rio dos Sinos - Unisinos \\ Endereço: Av. Unisinos, 950, Bairro Cristo Rei \\ CEP: 93022-000 - São Leopoldo/RS - Brasil \\ E-mail: ernani@unisinos.com.br \\ Telefone: (51) 3590-8186 \\ Charline Barbosa Pires \\ Mestre em Ciências Contábeis pela Unisinos \\ Endereço: Av. Unisinos, 950, Bairro Cristo Rei \\ CEP: 93022-000 - São Leopoldo/RS - Brasil \\ E-mail: charlinepires@uol.com.br \\ Telefone: (51) 3590-8186
}

\section{RESUMO}

As alterações ocorridas nas últimas décadas no ambiente de negócios têm afetado a atuação das empresas e, por conseqüência, o exercício da profissão contábil. Organismos internacionais como o IFAC, ISAR/UNCTAD, AICPA e AECC, preocupados com a capacidade das IES em formar profissionais contábeis capazes de atender às novas demandas dos empregadores, têm emitido relatórios que revelam as competências que os egressos dos

\footnotetext{
1 Artigo recebido em 12.01.2009. Revisado por pares em 07.03.2009. Reformulado em 28.04.2009. Recomendado em 30.04.2009 por Ilse Maria Beuren (Editora). Publicado em 02.02.2010. Organização responsável pelo periódico: FURB.
} 
cursos de Ciências Contábeis devem ter ao ingressar no mercado de trabalho visando, portanto, alinhar a estrutura curricular e as exigências do mercado. Nesse contexto, o objetivo desse artigo é apresentar um estudo comparativo das estruturas curriculares propostas pelo IFAC, ISAR/UNCTAD, AICPA e AECC e pela Resolução CNE/CES nº. 10/2004, especialmente no que tange às competências, habilidades e atitudes que devem ser desenvolvidas. Os resultados indicam que as diretrizes curriculares que orientam o desenho dos currícula de Ciências Contábeis no Brasil reconhecem a necessidade do desenvolvimento de competências relacionadas à formação profissional, complementada por conhecimentos organizacionais, administrativos e de TI, além do desenvolvimento de habilidades como: comunicação, liderança e interpessoais, alinhando-se, assim, com as propostas de organismos como IFAC, ISAR/UNCTAD, AICPA e AECC.

Palavras-chave: Contabilidade. Educação contábil. Estrutura curricular.

\section{ABSTRACT}

The changes that occurred in the business environment during the last few decades have affected the work of businesses and, consequently, the professional practice of accountancy. International organizations such as IFAC, ISAR/UNCTAD, AICPA and AECC, concerned about the capacity of IHE to train accountants who can respond to the new demands of employers, have issued reports that reveal the competencies required from graduates of accountancy courses, when they enter the job market, aiming, thus, to align the structure of the curriculum with the market demands. In this context, the present article aims to present a comparative study of the curricular structures proposed by IFAC, ISAR/UNCTAD, AICPA and AECC and by Resolution CNE/CES nr. 10/2004, especially regarding the competences, skills and attitudes that need to be developed. The results indicate that the curricular guidelines that guide the design of accountancy course curricula in Brazil acknowledge the need to develop competences related to professional training, complemented by knowledge of organization, administration and IT, besides the development of skills such as: communication, leadership and interpersonal relations, thus becoming aligned with the proposals made by organizations such as IFAC, ISAR/UNCTAD, AICPA and AECC.

Keywords: Accountancy. Accounting education. Curricular structures.

\section{INTRODUÇÃO}

De acordo com a Lei de Diretrizes e Bases da Educação Nacional (LDB), Lei $\mathrm{n}^{0}$ 9.394/96 (BRASIL, 1996), as Instituições de Ensino Superior (IES) têm como finalidade "formar diplomados nas diferentes áreas de conhecimento, aptos para inserção em setores profissionais e para a participação no desenvolvimento da sociedade brasileira e colaborar na sua formação contínua".

O mercado de trabalho dos contadores é composto, do lado da demanda, pelas organizações e demais usuários dos serviços contábeis, considerados como clientes das IES. Estas devem atender às suas necessidades através do "produto" que colocam no mercado - o bacharel em Ciências Contábeis, viabilizando por meio dos currícula dos cursos o desenvolvimento e o aprimoramento das habilidades e dos conhecimentos requeridos para que ele possa desempenhar suas atividades de maneira adequada.

Nelson, Baylei e Nelson (1998) afirmam que as organizações e as empresas de contabilidade consideram-se clientes da educação contábil e esperam que as suas necessidades 
com relação às competências dos alunos formados em Contabilidade sejam atendidas pelos educadores, ou seja, pelas instituições de ensino superior.

Desta forma, as IES que estão preocupadas em formar profissionais competentes e competitivos devem levar em consideração o ambiente no qual o futuro contador desempenhará suas atividades, ou seja, estar atentas à necessidade de aderência entre o ensino ofertado e as exigências do mercado de trabalho, isto porque o desenho de um curso orientado para o mercado pode se tornar um diferencial competitivo para os usuários dos serviços realizados pelos profissionais contábeis, para estes profissionais e para as próprias IES.

Para os usuários dos serviços contábeis, porque a escolha de um currículo adequado permite que sejam atendidas as suas demandas por mão-de-obra qualificada e apta a desempenhar suas atividades de maneira satisfatória.

Para os profissionais e para aqueles que pretendem atuar na área contábil, interessados em conquistar e garantir uma boa colocação no mercado, porque podem ter a chance de desenvolver as habilidades e conhecimentos requisitados pelos empregadores potenciais, seja realizando atividades tradicionalmente relacionadas à contabilidade (auditoria, contabilidade financeira, fiscal) ou aproveitando as oportunidades propiciadas pelo novo ambiente de negócios.

Para as instituições de ensino, porque ao estarem inseridas em um mercado cada vez mais competitivo, têm maiores chances de garantir sua continuidade caso sejam capazes de identificar, desenvolver e aprimorar os conhecimentos, habilidades e atitudes que caracterizam um contador competente, já que a tendência é de que instituições cuja excelência é reconhecida pelo mercado devem atrair um maior número de alunos.

Assim sendo, impõe-se o conhecimento do mercado de trabalho na elaboração do projeto pedagógico e estrutura curricular do curso, para identificar as competências exigidas do profissional que atuará na área contábil, desenvolvendo neste o perfil que atenda as demandas do mercado.

No Brasil, a Resolução do Conselho Nacional de Educação CNE/CES n ${ }^{0}$ 10/2004 definiu as Diretrizes Curriculares a serem observadas pelas IES na elaboração da organização curricular do curso de Ciências Contábeis, estabelecido por meio de um Projeto Pedagógico. A Resolução trata do perfil desejado do formado; das competências e habilidades desejadas; e dos conteúdos curriculares.

Organismos internacionais têm exposto suas preocupações com a formação do profissional contábil, emitindo documentos em que apontam o perfil desejado deste profissional, levando em conta as demandas do mercado. Este perfil deve estar alicerçado em conhecimentos e habilidades que também são apresentados pelos mencionados organismos nos documentos emitidos.

Postos esses elementos, definiu-se como problema de pesquisa a seguinte questão: Existe alinhamento entre a estrutura curricular recomendada pela CNE para o curso de Ciências Contábeis no Brasil e as que são propostas pelos organismos internacionais? Para responder à questão de pesquisa, este estudo tem como objetivo comparar a estrutura curricular estabelecida pelo CNE para o curso de Ciências Contábeis no Brasil, com as que são propostas pelos organismos internacionais.

Para tal, realiza-se uma análise comparativa na qual são descritos os principais elementos que compõem as referidas estruturas curriculares, com detalhamento das competências e habilidades que lhes dão suporte. 


\section{REFERENCIAL TEÓRICO}

\subsection{Estudos empíricos sobre o perfil do profissional contábil}

Nos últimos anos têm sido realizados diversos estudos empíricos tendo como tema o perfil do profissional contábil, envolvendo profissionais, educadores e empregadores. Siegel, Kulesza e Sorensen (1997) colheram subsídios com 800 Contadores Públicos e outros profissionais da área contábil que participaram em sua pesquisa nos Estados Unidos. Os pesquisadores solicitaram que os respondentes nomeassem e ordenassem por ordem de importância as atividades e responsabilidades que eles acreditavam que seus empregadores iriam valorizar nos próximos anos.

O resultado foi uma variedade de tarefas, muitas inexistentes há alguns anos atrás, que envolviam: a) determinação da lucratividade do cliente e do produto; b) melhoria de processos; c) avaliação de desempenho; d) planejamento estratégico de longo prazo; e) sistemas de computação e operações; f) sistemas contábeis de custos; g) atuação em fusões, aquisições e desinvestimentos; h) projeções; i) educação da organização; j) consultoria externa; k) análise econômica e financeira; e 1) sistemas de qualidade e de controle. Os resultados apresentados por Siegel, Kulesza e Sorensen (1997) evidenciam a expansão do campo de atuação do profissional contábil e a necessidade do desenvolvimento de um novo conjunto de conhecimentos e habilidades que o habilite a desempenhar as novas atividades identificadas pelos pesquisados.

Porter e Carr (1999) abordaram em sua pesquisa o processo de desenvolvimento, modificação e implementação de um novo programa de Contabilidade em uma universidade da Nova Zelândia. Os autores relatam que em uma das etapas do processo de elaboração de currículo foi realizada uma pesquisa com os stakeholders do programa a fim de averiguar os atributos, habilidades e conhecimentos que eles consideravam importantes para o profissional contábil. A pesquisa envolveu a realização de entrevistas, questionários e grupos de discussão com 16 grupos identificados de stakeholders, classificados nas seguintes categorias: estudantes presentes e futuros; empregadores; entidades de classe com interesses nos cursos e nos graduados em Contabilidade; autoridades reguladoras e comunidade local e acadêmica.

Os resultados do estudo apontaram que além dos conhecimentos técnicos requeridos pelo órgão que regula a profissão contábil na Nova Zelândia, as seguintes competências deveriam ser apresentadas pelos profissionais: a) habilidade de aprender; b) capacidade de aplicação prática das habilidades adquiridas; c) conhecimento de TI; d) habilidade de resolver problemas; e) habilidade de análise e síntese; f) habilidade de pensar analítica, crítica e criativamente; g) habilidades interpessoais e de comunicação; h) capacidade de identificar os sinais do ambiente de negócios (fatores micro e macro, meio ambiente, desenvolvimento sustentável, entre outros); i) conhecimento de diferentes culturas e línguas estrangeiras; j) habilidade de gerenciar o tempo, foco em objetivos, autoconfiança, motivação e auto-estima; k) habilidade de gerenciar equipes, melhorando o desempenho e a dinâmica dos grupos de trabalho; 1) conhecimentos de administração estratégica; e, m) comportamento ético. Os autores do estudo destacam que também se esperava que os graduados possuíssem conhecimentos profundos das matérias básicas de Contabilidade, mas que eles deveriam desenvolver conhecimentos relacionados à administração dos negócios e de tecnologia da informação, bem como habilidades de pensar analítica e criticamente.

Albrecht e Sack (2000) realizaram uma pesquisa com profissionais e educadores da área contábil, e identificaram a necessidade do desenvolvimento de conhecimentos mais amplos do que aqueles relacionados à contabilidade tributária e fiscal. Quanto perguntados sobre quais seriam as atividades que os graduados em contabilidade estariam realizando no 
futuro, os profissionais contábeis indicaram que os serviços mais demandados seriam, nesta ordem: 1) Análise financeira; 2) Planejamento financeiro; 3) Elaboração de Demonstrações Contábeis; 4) Consultoria estratégica; e 5) Consultoria de Sistemas. Os educadores, por outro lado, acreditavam que os serviços de auditoria seriam os mais demandados.

Albrecht e Sack (2000) também procuraram descobrir como seria, na opinião dos profissionais e dos educadores, a demanda por determinados tipos de atividades ligadas à Contabilidade. Tanto profissionais quanto professores concordaram que se manteria a demanda por atividades relacionadas à auditoria interna tradicional, contabilidade/finanças corporativas, contabilidade tributária e serviços de auditoria, e que novas oportunidades de trabalho surgiriam nas atividades de planejamento estratégico e consultoria.

Stone, Hunton e Wier (2000) investigaram a relação entre os conhecimentos/habilidades e o nível hierárquico na prática de contabilidade gerencial. Apuraram diferenças dos níveis hierárquicos na variabilidade do conhecimento dos contadores gerenciais no nível inicial; do conhecimento do setor (práticas, controles e sistemas de cada setor); do conhecimento gerencial tácito (capacidade de gerenciar a produtividade individual e a carreira e de construir relações de trabalho); e das capacidades. A pesquisa realizada com 2.941 contadores que atuavam nos setores de papel, impressão e publicação e produtos químicos, apontou que concomitante ao crescimento do nível hierárquico era: a) crescente o nível conhecimentos técnicos inicias medido; b) crescente o nível medido de conhecimento de um setor, especificamente; c) crescente o nível conhecimentos gerenciais tácitos; e, d) a habilidade para resolver problemas.

Coelho (2000) procurou identificar os conhecimentos mais requeridos, na prática, aos profissionais contábeis no município do Rio de Janeiro. O autor analisou 63 questionários encaminhados às empresas e 387 anúncios com ofertas de emprego publicadas em jornais de grande circulação no município, de janeiro a dezembro de 1999. As respostas aos questionários indicaram que as principais atribuições do profissional contábil estavam relacionadas às rotinas e práticas gerais de contabilidade, finanças e custos (32\%); e à legislação fiscal e tributária (25\%). As atividades mais realizadas eram: análise de balanços e do comportamento de despesas e receitas $(85 \%)$; planejamento tributário e elaboração de cálculos, análises e interpretação de amostragens aleatórias ou probabilísticas (67\%); elaboração de orçamentos financeiros, econômicos, patrimoniais e de investimentos, bem como acompanhamento da execução e análise das variações orçamentárias (66\%); preparação de declaração de IR (66\%); e classificação dos fatos e registros contábeis (60\%).

No que diz respeito às características pessoais, Coelho (2000) identificou que os atributos principais do profissional contábil, na opinião dos respondentes, eram: Ética profissional (82\%); Iniciativa (79\%); Organização (78\%); Adaptabilidade às inovações (70\%); Negociação para trabalho em equipe (64\%); e Habilidade de comunicação oral e escrita (64\%). Já os conhecimentos não relacionados especificamente à Contabilidade, apontados como importantes pelos respondentes foram: Direito/Legislação fiscal e tributária (99\%); Administração (43\%); Análise de investimentos e mercado de capitais (31\%); Matemática e Estatística (29\%); Economia (19\%); Sociologia e Psicologia (6\%). Ao analisar as ofertas de emprego, Coelho (2000) verificou que o principal conhecimento exigido dizia respeito à Legislação fiscal e tributária (35\%); seguido por conhecimentos em Contabilidade Geral (20\%); Finanças (16\%); Custos (11\%); Legislação Trabalhista (11\%); e Contabilidade Internacional (10\%). Além disso, os profissionais deveriam possuir conhecimento em informática e idiomas, principalmente em inglês.

Siqueira e Soltelinho (2001) analisaram as exigências do mercado de trabalho no que diz respeito, especificamente, às características do profissional que ocupa o cargo de Controller. Os autores analisaram 51 anúncios publicados no Caderno de Domingo do Jornal 
do Brasil durante os anos de 1960, 1969, 1989, 1991, 1992 e 1999. Constataram que as empresas contratantes eram, em sua maioria, de grande porte, priorizavam os profissionais com formação em Ciências Contábeis e que desejavam aqueles que possuíam experiência, tinham profundos conhecimentos em informática, dominavam uma ou mais línguas estrangeiras, eram comunicativos e capazes de liderar e trabalhar em equipe.

Brussolo (2002) levou em consideração a existência de uma relação entre as habilidades exigidas do profissional e o cargo hierárquico ocupado. A partir da análise de 1.950 anúncios de empregos publicados em jornais e em sites de recolocação profissional e revistas especializadas em administração de carreira, no período de janeiro a outubro de 2001, o autor identificou que, quanto maior o nível hierárquico, maior é a exigência por habilidades gerencias. Observou também que, enquanto os conhecimentos em Informática e Experiência Anterior são exigidos para todos os níveis hierárquicos, conhecimentos sobre Direito, Legislação, Contabilidade Societária e Tributária são exigidos por 99,3\% das ofertas pesquisadas para os cargos de nível auxiliar e por $98,7 \%$ das oportunidades de emprego para o nível técnico, sendo que este percentual decresce na medida em que o nível hierárquico evolui. Já os conhecimentos relacionados à Gestão Empresarial, Normas Internacionais, Economia, Administração, Finanças e Idiomas, são mais solicitados aos profissionais que pretendem ocupar cargos de gerência.

Silva (2003, p. 208) analisou 2.400 ofertas de emprego dirigidas aos Contadores da cidade de São Paulo, publicadas em jornais e sites de recolocação no período de janeiro a dezembro de 2002, identificando que "[...] o mercado de trabalho busca profissionais qualificados e não simplesmente diplomados [...]". A autora concluiu que o domínio das habilidades técnicas ainda tem sido mais requerido que as habilidades humanas (trabalhar em equipes) e conceituais (de resolver problemas e de pensar analiticamente), mas acredita que este perfil começa a sofrer alterações e a tendência é de que cada vez mais a atuação contábil se integre com as demais áreas de conhecimento, como: Administração, Direito, entre outras, e o Contador passe a assumir uma condição de estrategista, mais preocupado com questões gerenciais do que com questões fiscais e de escrituração.

Evangelista (2005) identificou em sua pesquisa o perfil do profissional contábil desejado pelas grandes empresas localizadas na cidade de São Paulo, mediante análise das respostas de 77 questionários, e constatou que estas esperavam que ele fosse capaz de: a) empregar seus conhecimentos de forma a agregar valor para a empresa; b) disseminar seus conhecimentos, compartilhando-os com os demais colegas de trabalho; c) relacionar-se bem com as pessoas e as demais áreas organizacionais; d) adaptar-se com facilidade às mudanças implementadas; e) ser um profissional ético; f) ser criativo em suas funções; g) ter preocupações políticas e sociais; h) organizar o seu trabalho e o da sua equipe; i) organizar, implantar e administrar um sistema de informações gerenciais; j) trabalhar com números (habilidade de cálculo e de interpretações); k) buscar solução para os problemas empresariais através do emprego de métodos quantitativos; 1) ser responsável pela avaliação do desempenho econômico, financeiro e mercadológico da organização; $\mathrm{m}$ ) ter facilidade de comunicação e de apresentação em público; e, n) assumir o papel de articulador e negociador com as diversas áreas organizacionais.

A pesquisa de Evangelista (2005) revelou que as demandas do mercado de trabalho ultrapassam os conhecimentos relacionados à Contabilidade Financeira e Tributária, uma vez que estes devem ser complementados por conhecimentos e habilidades que possibilitem o desempenho de atividades voltadas à gestão das empresas.

Guimarães (2006) analisou 4.107 ofertas de emprego publicadas em jornais e em sites de recolocação profissional. $\mathrm{O}$ autor procurou identificar o perfil do contador requerido pelo mercado de trabalho da Região Metropolitana de São Paulo (RMSP), expresso nas ofertas 
públicas de emprego. Constatou que o mercado tem procurado por profissionais capazes de atuar na gestão das organizações e que acompanhem, em termos de qualificação, o dinamismo das mudanças ocorridas no cenário macroeconômico.

As características apontadas como relevantes pelos autores citados têm em comum o fato de que se espera que o profissional contábil, além de possuir competências tradicionalmente relacionadas à Contabilidade (societária, tributária e auditoria), esteja apto a participar da gestão da entidade, comunicando suas idéias e interagindo com as demais áreas organizacionais, não apenas identificando problemas, mas contribuindo para a sua solução. Tais expectativas do mercado de trabalho, por sua vez, devem ser consideradas pelas IES e contempladas nos currícula dos cursos.

\subsection{Currículo do curso de graduação em Ciências Contábeis no Brasil}

As diretrizes curriculares que devem ser observadas pelas IES nos cursos de graduação em Ciências Contábeis são definidas pela Resolução CNE/CES nº 10/2004. Esta resolução determina que a organização curricular do curso deva ser estabelecida por meio de um Projeto Pedagógico que contemple a descrição dos seguintes aspectos:

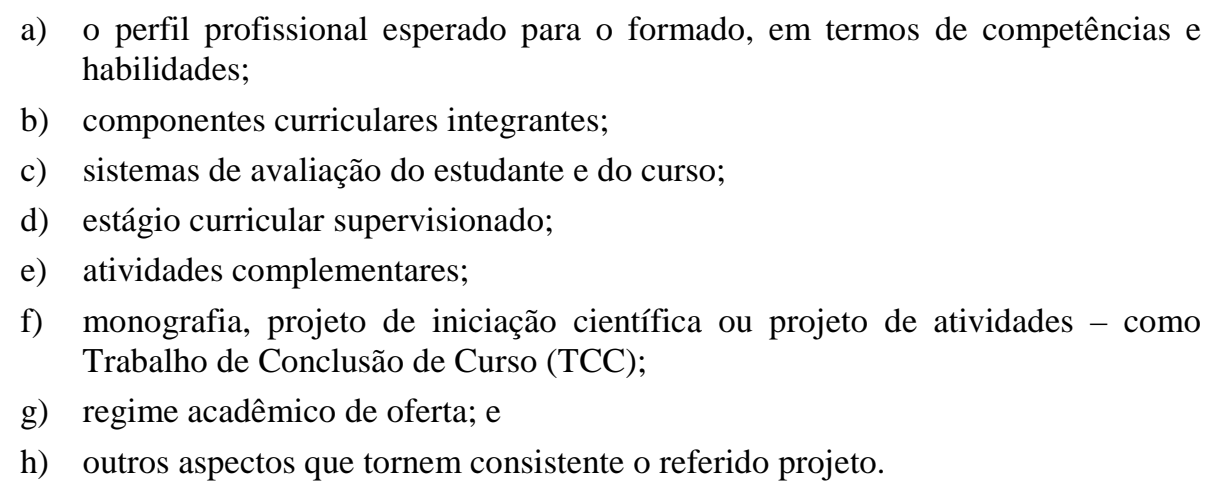

Entre as determinações da resolução merecem destaque as que estão relacionadas ao que segue: a) ao perfil desejado do formado; b) às competências e habilidades desejadas; e, c) aos conteúdos curriculares.

Quanto ao perfil profissional desejado, a resolução estabelece que o aluno formado deva ser capaz de:

a) compreender questões científicas, técnicas, sociais, econômicas e financeiras, tanto em âmbito nacional quanto internacional, independentemente do tipo de entidade em que atua;

b) dominar as responsabilidades funcionais que envolvam apurações, auditorias, perícias, arbitragens, noções de atividades atuariais e de quantificações de informações financeiras, patrimoniais e governamentais, demonstrando domínio das inovações tecnológicas; e

c) revelar capacidade crítico-analítica de avaliação, no que diz respeito às implicações das novas tecnologias de informação nas atividades da organização.

Já as competências e habilidades que a IES deve desenvolver no egresso do curso de graduação em Ciências Contábeis são as seguintes:

a) conhecer a terminologia e a linguagem das Ciências Contábeis e Atuariais, bem como usá-las adequadamente; 
b) possuir uma visão sistêmica e interdisciplinar da atividade contábil;

c) elaborar pareceres e relatórios que atendam as necessidades dos usuários, independentemente do tipo de organização;

d) aplicar de maneira adequada a legislação relacionada às funções contábeis;

e) liderar equipes multidisciplinares no processo de captação dos insumos necessários ao controle técnico e à geração e disseminação de informações contábeis;

f) exercer suas responsabilidades demonstrando domínio das funções contábeis, viabilizando aos agentes econômicos e administradores de qualquer tipo de organização o cumprimento de seus encargos quanto ao gerenciamento, controle e prestação de contas de sua gestão à sociedade em geral, além de gerar informações para a tomada de decisão, organização de atitudes e construção de valores orientados para a cidadania;

g) desenvolver, analisar e implementar sistemas de informações, tanto contábeis quanto gerenciais; e

h) exercer com ética e proficiência as atribuições e prerrogativas que lhes são prescritas através da legislação específica.

Para Souza e Ortiz (2006), as habilidades e competências definidas pela resolução explicitam uma preocupação com o desenvolvimento do pensamento crítico do egresso, ampliando a sua participação no contexto empresarial.

Por fim, quanto aos conteúdos curriculares, a Resolução CNE/CES n ${ }^{\circ}$ 10/2004 define que as IES, ao organizarem seus currícula, devem estabelecer conteúdos: (a) de formação básica; (b) de formação profissional; e (c) de formação teórico-prática (Apêndice A).

As determinações da Resolução CNE/CES n ${ }^{\circ}$ 10/2004 são amplas e flexíveis, o que significa que cabe a cada IES definir, por exemplo, quais as disciplinas a serem ministradas e o número de horas-aula destinadas a cada conteúdo, desde que as diretrizes estabelecidas sejam observadas, ou seja, desde que os conteúdos curriculares sejam contemplados.

Souza e Ortiz (2006) entendem que a Resolução CNE/CES n ${ }^{0}$ 10/2004 permite uma maior mobilidade às IES, quando comparada aos antigos currícula mínimos que engessavam o ensino superior, pois eram pouco práticos e não possuíam conexão com as mudanças ambientais ocorridas. Os autores destacam que a referida resolução, ao contrário, permite que as IES realizem alterações de forma a atender as necessidades e demandas dos alunos, do mercado e da sociedade.

Na opinião de Dutra (2003), o fato das IES atualmente possuírem autonomia quanto aos conteúdos contemplados em seus currícula comporta duas facetas distintas. A primeira diz respeito à autonomia, que permite que a IES defina a sua própria política educacional; já a segunda, está relacionada ao encargo que isto acarreta, pois esta é responsável pela definição de seus próprios currícula e, por esta razão, não pode mais atribuir a terceiros a culpa por eventuais problemas.

Essa argumentação implica que as IES devem planejar, da melhor maneira possível, suas atividades de ensino-aprendizagem. E como o currículo dos cursos é uma parte importante desta atividade, conseqüentemente, atenção especial deve ser dada na definição desta peça pedagógica (DUTRA, 2003, p. 2).

Observa-se, então, que a identificação das necessidades do mercado, no que diz respeito às qualificações do futuro profissional contábil formado pelas IES é importante, uma 
vez que tais informações podem contribuir para o planejamento de currícula que possibilitem a formação de indivíduos preparados para satisfazer as demandas do mercado de trabalho.

\subsection{Perfil do profissional contábil na visão de organismos internacionais}

\subsubsection{International Federation of Accountants (IFAC)}

A International Federation of Accountants - IFAC foi fundada em 1977 por 63 organismos ligados à Contabilidade, entre eles o Instituto dos Auditores Independentes do Brasil - IBRACON, durante o $11^{\circ}$. Congresso Mundial de Contadores realizado na Alemanha (IFAC, 2008).

Desde então, a IFAC tem criado uma série de conselhos e comitês voltados para o desenvolvimento de padrões e normas internacionais, focados em setores específicos da profissão contábil, entre eles o International Accounting Education Standards Board, o Comitê de Educação, criado em 1977 (IFAC, 2008).

O Comitê de Educação objetiva promover a qualidade do ensino de Contabilidade mediante a definição de orientações que visam à promoção da melhoria dos padrões aplicáveis à educação contábil em todo o mundo. Este Comitê elabora três tipos de publicações:

a) os Padrões Internacionais de Educação (International Education Standards - IES), que descrevem os padrões geralmente aceitos no processo de educação e desenvolvimento do profissional de Contabilidade;

b) os Guias de Educação Profissional para Contadores (International Education Guidelines for Professional Accountants - IEG), que auxiliam os membros da IFAC na implementação dos padrões internacionais definidos; e

c) os Papers de Educação Internacional para Contadores (International Education Papers for Professional Accountants - IEP), que promovem a discussão e o debate de assuntos relacionados à educação e que afetam a profissão contábil, explicando, examinando, analisando e avaliando de forma crítica os temas e práticas educacionais.

Os conhecimentos e habilidades inerentes ao profissional de Contabilidade, na visão

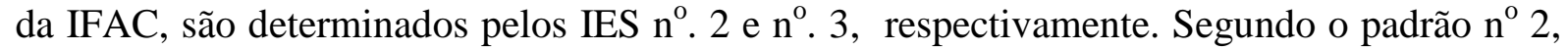
os conhecimentos que devem ser apresentados pelo Contador dividem-se em: a) conhecimentos de contabilidade e finanças e áreas afins; b) conhecimentos organizacionais e de negócios; e, c) conhecimentos de tecnologia da informação (TI) (Apêndice A).

As habilidades estabelecidas pelo padrão $\mathrm{n}^{\text {o. }} 3$ estão segregadas em: a) intelectuais; (b) técnicas e funcionais; c) pessoais; d) interpessoais e de comunicação; e, e) organizacionais e de gerenciamento de negócios, apresentadas no Apêndice A.

Além dos conhecimentos e habilidades apresentados, a IFAC ressalta a importância da postura ética do profissional contábil, enfatizando que o “... comportamento ético é tão importante quanto às competências técnicas" (IFAC, 2003, p. 64).

\subsubsection{American Institute of Certified Public Accountants (AICPA)}

O American Institute of Certified Public Accountants (AICPA) foi fundado em 1887, sendo denominado naquela época de American Association of Public Accountants (AAPA), e assumindo a denominação atual apenas em 1957 (AICPA, 2008a). 
O organismo tem como objetivo disponibilizar aos seus membros, os Contadores Públicos americanos, recursos, informações e liderança que os possibilitem prestar seus serviços com qualidade, beneficiando a sociedade, seus empregadores e clientes; e uma de suas missões é encorajar indivíduos altamente qualificados a se tornar Contadores Públicos, além de dar suporte ao desenvolvimento de programas acadêmicos de excelência (AICPA, 2008a).

Nesse âmbito, o AICPA criou em 1999 o Core Competency Framework for Entry into the Accounting Profession, que contempla o modelo de competências-chave que devem ser apresentadas pelos contadores que estão ingressando do mercado de trabalho. As recomendações do modelo foram elaboradas a partir da opinião de mais de três mil profissionais contábeis (BOLT-LEE; FOSTER, 2003).

As competências definidas pelo AICPA, apresentadas no APÊNDICE A, são divididas em: a) funcionais, que correspondem às competências técnicas; b) competências pessoais, que dizem respeito aos comportamentos e atitudes que podem melhorar a forma como os indivíduos se relacionam com os demais e facilitar o aprendizado individual; e, c) competências de negócios, que se referem à compreensão dos ambientes interno e externo de negócios (AICPA, 2008b).

Os conhecimentos, habilidades e atitudes relacionadas (1) às competências funcionais incluem: modelagem de decisões; análise de risco; mensuração; relatórios; pesquisa; e uso da tecnologia da informação; (2) às competências pessoais incluem: comportamento profissional; resolução de problemas e tomada de decisão; interação; liderança; comunicação; gerenciamento de projetos; e uso da tecnologia da informação; (3) às competências de negócios, incluem: pensamento crítico e estratégico; visão do setor; perspectiva internacional/global; administração de recursos; perspectiva legal; marketing/ foco no cliente; e uso da tecnologia da informação.

O AICPA (2008b) destaca que o modelo de competências que foi proposto pode ser utilizado pelos educadores no processo de desenvolvimento e/ou reforma de currícula dos cursos de Ciências Contábeis.

\subsubsection{Accounting Education Change Commission (AECC)}

A Accounting Education Change Commission (AECC) foi criada em 1989 pela American Accounting Association (AAA) em parceria com as oito maiores empresas de auditoria da época (Big 8), com o objetivo de promover melhorias no processo de preparação dos profissionais contábeis (AECC, 1999).

A criação do organismo foi motivada pela preocupação com a falta de aproximação entre as qualificações exibidas pelos graduados em Contabilidade e aquelas requeridas pelo mercado de trabalho e resultou, entre outras iniciativas, na elaboração de um relatório expondo os conhecimentos e habilidades necessárias para o exercício da profissão contábil, que deveriam ser desenvolvidas pelas Instituições de Ensino.

A AECC entende que os indivíduos que ingressam na profissão contábil devem possuir um amplo grupo de conhecimentos dividido em três áreas: a) conhecimentos gerais; b) conhecimentos organizacionais e de negócios; e c) conhecimentos de contabilidade e de auditoria (Apêndice A).

As habilidades definidas pela AECC que devem ser apresentadas pelo profissional que deseja ser bem sucedido na profissão contábil se dividem em: a) habilidades de comunicação; b) habilidades intelectuais; e c) habilidades interpessoais, apresentadas no Apêndice A.

A AECC destaca que os conhecimentos e habilidades mencionados podem ser obtidos de três fontes distintas: a) do talento individual de cada um; b) das instituições de ensino; e c) do processo de desenvolvimento e educação continuada. 


\subsubsection{Intergovernmental Working Group of Experts on International Standards} of Accounting and Reporting / United Nations Conference on Trade and Development (ISAR/UNCTAD)

A United Nations Conference on Trade and Development (UNCTAD) é um órgão ligado à Organização das Nações Unidas (ONU) que, segundo Rosella et al. (2006), surgiu da necessidade de os países em desenvolvimento possuírem um Fórum voltado para a discussão de assuntos relacionados aos problemas enfrentados por eles no processo de inserção no comércio internacional.

O UNCTAD possui um grupo de especialistas em padrões contábeis internacionais, denominado Intergovernmental Group of Experts on International Standards of Accounting and Reporting (ISAR). Segundo Aggestam (1999), o ISAR é composto por órgãos governamentais e não-governamentais, sendo o único órgão intergovernamental da ONU voltado à promoção da harmonização das práticas de Contabilidade e de Auditoria.

Em 1999 o ISAR realizou a sua $16^{\text {a }}$ sessão da qual resultou a criação de um documento denominado Guideline on national requeriments for the qualification of the professional accountants, com o objetivo de estabelecer um padrão de comparação para a qualificação do profissional contábil, contribuindo para que ele se tornasse capaz de atuar em um mercado global e promover a harmonização das competências globais requeridas (ISAR/UNCTAD, 1999).

O conceito de qualificação global proposto pelo ISAR envolve a harmonização e qualificação dos profissionais contábeis que são atualmente educados e certificados com base nos modelos de cada país (AGGESTAM, 1999). O guia para qualificação dos profissionais contábeis elaborado pelo organismo contempla determinações acerca: a) da educação geral e das habilidades inerentes aos Contadores; b) da educação profissional; c) da verificação das competências profissionais (exame de suficiência); d) da experiência prática; e) da educação profissional continuada; e f) da certificação. As habilidades intelectuais, pessoais, de comunicação e de tecnologia da informação, definidas pelo ISAR, são as mesmas estabelecidas pela IFAC, já apresentadas.

Já os conhecimentos técnicos exigidos são definidos no item "educação profissional" e dividem-se em: a) conhecimentos administrativos e organizacionais; b) conhecimentos de tecnologia da informação; e c) conhecimentos contábeis e assuntos afins. Tais conhecimentos técnicos foram alterados na $20^{\mathrm{a}}$ sessão do ISAR em 2003, quando o documento elaborado em 1999 foi atualizado, dando origem ao Revised Model Accounting Curriculum (MC), que descreve de forma detalhada os conteúdos relacionados a cada um dos blocos de conhecimento.

Apesar de definir detalhadamente os conteúdos que devem ser contemplados nos currícula dos cursos de formação do profissional contábil, o ISAR salienta que as suas determinações representam apenas um guia que deve ser seguido pelas IES, às quais competem estabelecer as disciplinas a serem ministradas, bem como a carga horária de cada uma delas, observando as peculiaridades de cada país, como: as constantes mudanças no cenário econômico; as diferenças culturais e os avanços tecnológicos.

Segundo o MC, o currículo global para educação profissional contábil deve contemplar os conteúdos elencados no Apêndice A.

\section{PROCEDIMENTOS METODOLÓGICOS}

Em função dos objetivos deste estudo e com base em Silva e Menezes (2001), esta pesquisa é classificada como: a) aplicada, pois objetiva identificar a existência de alinhamento entre a estrutura curricular recomendada pela CNE para o curso de Ciências Contábeis no 
Brasil e as que são propostas pelos organismos internacionais; b) qualitativa, uma vez que se trata de uma análise comparativa dos principais elementos que compõem as estruturas curriculares analisadas; c) descritiva, pois descreve as diferenças e semelhanças existentes das referidas estruturas curriculares, no que diz respeito às competências e habilidades que lhes dão suporte; e, d) documental, porque tem como insumo a Resolução CNE/CES nº. 10/2004 e as orientações emitidas pelos organismos internacionais foco de estudo.

Para responder à questão de pesquisa, realizou-se uma análise comparativa do perfil do profissional contábil definido na Resolução CNE/CES $n^{\circ}$. 10/2004 e aqueles definidos pelos organismos internacionais estudados, segregando-se as habilidades e competências propostas pelas estruturas curriculares em categorias de análise estabelecidas a partir da revisão da literatura, que aponta que os Contadores devem possuir, além das competências relacionadas à Contabilidade, conhecimentos, habilidades e atitudes que lhes dêem condições de participar do processo de gestão das organizações.

Desta forma, as quatro categorias de análise definidas foram as seguintes: a) formação profissional (contabilidade e áreas a fins); b) conhecimentos administrativos e organizacionais; c) conhecimentos de TI; d) outros conhecimentos e habilidades, que permitem que os futuros profissionais interajam com as demais áreas organizacionais e participem ativamente da gestão da empresa.

As semelhanças e diferenças constatadas foram sumarizadas no quadro comparativo apresentado no Apêndice A, que serviu de base para a discussão dos resultados.

\section{APRESENTAÇÃO E DISCUSSÃO DOS RESULTADOS}

\subsection{Comparação entre a estrutura curricular do CNE/CES e as estruturas curriculares emanadas de organismos internacionais}

Examinando os elementos sumarizados na planilha apresentada no Apêndice A, constata-se que há diferentes abordagens nas estruturas curriculares divulgadas pelos organismos internacionais. O Quadro 1 sumariza a análise comparativa entre as estruturas curriculares analisadas.

\begin{tabular}{|c|c|}
\hline Categorias de Análise & $\begin{array}{c}\text { Principais semelhanças / diferenças entre as estruturas curriculares } \\
\text { analisadas }\end{array}$ \\
\hline Contabilidade e áreas afins & $\begin{array}{l}\text { Reconhece-se a importância do desenvolvimento de conhecimentos } \\
\text { relacionados não apenas à Contabilidade Societária, Tributária e } \\
\text { Auditoria, mas também à Contabilidade Gerencial. }\end{array}$ \\
\hline $\begin{array}{l}\text { Conhecimentos Administrativos e } \\
\text { Organizacionais }\end{array}$ & $\begin{array}{l}\text { A Resolução CNE se aproxima das recomendações do IFAC, AECC e } \\
\text { ISAR/UNCTAD, embora não apresente detalhamentos dos conteúdos que } \\
\text { devem ser desenvolvidos. }\end{array}$ \\
\hline Tecnologia da Informação & $\begin{array}{l}\text { As propostas dos organismos são semelhantes ao definido na Resolução } \\
\text { CNE. }\end{array}$ \\
\hline Habilidades & $\begin{array}{l}\text { Reconhece-se a importância do desenvolvimento e aprimoramento de } \\
\text { habilidades que facilitam a interação com as demais áreas } \\
\text { organizacionais, a tomada de decisão e a gestão das organizações; } \\
\text { O componente ético é comum a todas as estruturas curriculares. }\end{array}$ \\
\hline Outros Conhecimentos & $\begin{array}{l}\text { O campo "Conteúdo de Formação Teórico-Prática" está presente apenas } \\
\text { na Resolução CNE, mas também é prevista pelo ISAR/UNCTAD no } \\
\text { campo "Formação Profissional". }\end{array}$ \\
\hline
\end{tabular}

Quando 1 - Análise comparativa das estruturas curriculares

Fonte: elaboração própria. 
Encontra-se maior semelhança entre a abordagem da IFAC e do ISAR/UNCTAD, as quais têm pontos comuns com a estrutura proposta às IES no Brasil, no campo destinado aos 'conhecimentos relacionados à formação profissional'. O AICPA trata neste campo das 'competências funcionais', com uma abordagem mais genérica, e a AECC de 'conhecimentos de contabilidade e auditoria', portanto, com uma abordagem mais restrita. Todos os órgãos, porém, apontam a necessidade do desenvolvimento de conhecimentos relacionados não apenas à contabilidade societária, tributária e auditoria, mas também à contabilidade gerencial.

No campo destinado aos 'conhecimentos administrativos e organizacionais', três organismos internacionais (IFAC, AECC e ISAR/UNCTAD) apresentam similitude em suas propostas, tratando dos conhecimentos organizacionais e de negócios (administrativos), enquanto o AICPA mantém também nesse campo uma abordagem mais genérica, adotando a terminologia "competências de negócios". Percebe-se que a estrutura recomendada no Brasil se aproxima bastante das recomendações do IFAC, AECC e ISAR/UNCTAD, embora seja mais sucinta e não mencione quais conhecimentos relacionados à Administração, por exemplo, deveriam ser desenvolvidos pelas IES.

No campo denominado 'tecnologia da informação', observa-se bastante semelhança nas propostas dos organismos com o estabelecido na Resolução do CNE, uma vez que todos entendem que os conhecimentos, habilidade e atitudes devem ser desenvolvidos de forma a preparar os futuros contadores para a utilização dos recursos da TI na realização de suas atividades.

No tocante às 'habilidades', observa-se que o desenvolvimento e o aprimoramento daquelas que facilitariam a interação com as demais áreas, a tomada de decisão e o desempenho de atividades ligadas à gestão da organização, é recomendado tanto pela Resolução do CNE quanto pelos organismos internacionais. As propostas da IFAC e do ISAR/UNCTAD são iguais, bem detalhadas, e se aproximam muito da proposta da AECC. As habilidades expressas na Resolução do CNE também estão alinhadas às já referidas, mas não são apresentadas na estrutura curricular propriamente dita. O AICPA utiliza a expressão 'competências pessoais' neste campo, porém, de certa maneira descreve elementos comuns às habilidades descritas nas estruturas curriculares dos demais organismos e do CNE.

Outro elemento que é comum a todas as estruturas curriculares examinadas é o componente ético. O campo 'conteúdos de formação teórico-prática', por sua vez, está presente somente na estrutura da Resolução do CNE, sendo que a realização de atividades práticas pelos discentes também está prevista na proposta do ISAR/UNCTAD que recomenda 'estágio em contabilidade' no campo 'conhecimentos relacionados à formação profissional'.

\section{CONSIDERAÇÕES FINAIS}

A revisão bibliográfica evidenciou que os conhecimentos inerentes ao profissional contábil são mais amplos do que aqueles tradicionalmente relacionados à Contabilidade, como contabilidade societária e tributária e auditoria, revelando a demanda do mercado de trabalho por contadores capazes de interagir com as demais áreas organizacionais e participar ativamente do processo decisório.

Embora as diretrizes curriculares propostas pela Resolução do CES/CNE nº 10/2004 e pelos organismos analisados (Apêndice A) possuam algumas divergências, o estudo comparativo revelou vários pontos em comum.

Constatou-se que as diretrizes curriculares que orientam o desenho dos currícula de Ciências Contábeis no Brasil reconhecem a necessidade do desenvolvimento de competências relacionadas à formação profissional, complementada por conhecimentos organizacionais e administrativos e de TI e o desenvolvimento de habilidades como comunicação, liderança e 
interpessoais. Portanto, considera, assim como o IFAC, ISAR/UNCTAD, AICPA e AECC, as necessidades do mercado de trabalho.

\section{REFERÊNCIAS}

AECC - Accounting Education Change Commission. The Accounting Education Change Commission: its history and impact. Sarasota, 1999. Disponível em: < http://aaahq.org/aecc/history/cover.htm> Acesso em: 1 dez. 2006.

AGGESTAM, Caroline. Towards a global accounting qualification? A report from the $16^{\text {th }}$ Session of the ISAR Group of the UN Palais de Nations, Geneva, 17-19 February 1999. The European Accounting Review, v. 8, n. 4, dez. 1999, p. 805-813. doi:10.1080/096381899335835

AICPA - American Institute of Certified Public Accountants. History of the AICPA. Disponível em: < http://www.aicpa.org/About+the+AICPA/Understanding+the+ Organization/History+of+the+AICPA.htm> Acesso em: 29 set. 2008a.

AICPA - American Institute of Certified Public Accountants. The AICPA Core Competency Framework for Entry into the Accounting Profession. New York, 1999. Disponível em: <http://www.aicpa.org/edu/func.htm> Acesso em: 3 jan. 2008b.

ALBRECHT, W. Steve; SACK, Robert J. Accounting education: charting the course through a perilous future. Accounting Education Series, n. 16, 2000.

BOLT-LEE, Cynthia; FOSTER, Sheila D. The Core Competence Framework: a new element in the accounting call for accounting education change in the United States. Accounting Education, v. 12, n. 1, mar. 2003, p. 33-47. doi:10.1080/0963928031000074486

BRASIL. Lei n⿳0. 9.324, de 20 de novembro de 1996. Lei de Diretrizes e Bases da Educação Nacional (LDB). Estabelece as diretrizes e bases da educação nacional. In: SENADO FEDERAL. Legislação Republicana Brasileira. Brasília, 1996. Disponível em: <http://www6.senado.gov.br/sicon/Pagina Documentos.action>. Acesso em: 12 nov. 2006.

BRASIL. Resolução CNE/ CES no. 10, de 16 de dezembro de 2004. Institui as Diretrizes Nacionais Curriculares para o Curso de Graduação em Ciências Contábeis, bacharelado, e dá outras providências. In: CONSELHO NACIONAL DE EDUCAÇÃO - CÂMARA DE EDUDAÇÃO SUPERIOR. Legislação Republicana Brasileira. Brasília, 2004. Disponível em: <http://portal.mec.gov.br/cne/arquivos/pdf/ rces10_04.pdf>. Acesso em: 12 nov. 2006.

BRUSSOLO, Fábio. As diretrizes curriculares dos cursos de graduação em Ciências Contábeis $x$ o mercado de trabalho através das ofertas de emprego para a área contábil na Grande São Paulo: uma análise crítica. Dissertação (mestrado). Centro Universitário Álvares Penteado, São Paulo, 2002.

COELHO, Cláudio U. F. O ensino superior de contabilidade e o mercado de trabalho: uma análise no município do Rio de Janeiro. 2000. Dissertação (Mestrado) - Universidade Federal do Rio de Janeiro, Rio de Janeiro, 2000.

DUTRA, Oneide Tadeu. Proposta de uma matriz curricular para o curso de Ciências Contábeis na Grande Florianópolis. 2003. Dissertação (Mestrado) - Universidade de São Paulo, São Paulo, 2003.

EVANGELISTA, Armindo Aparecido. O currículo dos cursos de Ciências Contábeis e o mercado de trabalho para o profissional contador. 2005. Dissertação (Mestrado) - Centro Universitário Álvares Penteado, São Paulo, 2005. 
GUIMARÃES, Paulo Cézar. Identificação do perfil profissiográfico do profissional de Contabilidade requerido pelas empresas através de ofertas de emprego na Região Metropolitana de São Paulo. 2006. Dissertação (Mestrado) - Centro Universitário Álvares Penteado, São Paulo, 2006.

INTERNATIONAL FEDERATION OF ACCOUNTANTS (IFAC). IFAC history in brief. Disponível em: <http://www.ifac.org/History/>. Acesso em: 29 set. 2008.

INTERNATIONAL FEDERATION OF ACCOUNTANTS (IFAC). International education Standards for professional accountants. New York, 2003.

NELSON, Irvin T.; BAILEY, James A; NELSON, Tom. Changing accounting education with purpose: market-based strategic planning for departments of accounting. Issues in Accounting Education, v. 13, n. 2, maio, 1998, p. 301-326.

PORTER, Brenda A.; CARR, Shirley. Form the strategic plan to practical realities: developing and implementing a zero-based accounting curriculum. Issues in Accounting Education, v. 14, n. 4, nov. 1999, p. 565-588. doi:10.2308/iace.1999.14.4.565

ROSELLA, Maria Helena et al. O ensino superior no Brasil e o ensino da contabilidade. In: PELEIAS, Ivam R. (org.) Didática do ensino da contabilidade: aplicável a outros cursos superiores. São Paulo: Saraiva, 2006. p. 1-59.

SIEGEL, Gary; KULESZA, C. S.; SORENSEN, James E. Are you ready for the new accounting? Journal of Accountancy, v. 184, n. 2, ago. 1997, p. 42-46.

SILVA, Marli Rozendo. Contribuição à melhoria da atuação profissional do contador da cidade de São Paulo: pesquisa face às exigências do mercado de trabalho. Dissertação (Mestrado) - Centro Universitário Álvares Penteado, São Paulo, 2003.

SIQUEIRA, José R. Maia de; SOLTELINHO, Wagner. O profissional de controladoria no mercado brasileiro - do surgimento da profissão aos dias atuais. Revista Contabilidade \& Finanças - USP, São Paulo, n. 27, 2002, p. 66-77.

SOUZA, Márcio B.; ORTIZ, Herculano C. A estrutura básica para o ensino superior de Contabilidade. In: PELEIAS, Ivam R. (org.) Didática do ensino da Contabilidade: aplicável a outros cursos superiores. São Paulo: Saraiva, 2006. p. 121-178.

STONE, Dan N.; HUNTON, James E.; WIER, Benson. Succeeding in managerial accounting. Part 1: knowledge, ability, and rank. Accounting, Organizations and Society, v. 25, n. 7, out. 2000, p. 697-715. doi:10.1016/S0361-3682(99)00063-X

UNITED NATIONS CONFERENCE ON TRADE AND DEVELOPMENT (UNCTAD). Guideline on National Requirements for the Qualification of Professional Accountants. New York/Geneve, 1999.

UNITED NATIONS CONFERENCE ON TRADE AND DEVELOPMENT (UNCTAD). Revised model accounting curriculum (MC). New York/Geneve, 2003. 


\section{APÊNDICE A - QUADRO COMPARATIVO DAS ESTRUTURAS CURRICULARES}

\begin{tabular}{|c|c|}
\hline $\begin{array}{c}\text { Organis- } \\
\text { mos }\end{array}$ & Estuturas Curriculares \\
\hline \multicolumn{2}{|c|}{ Conhecimentos relacionados à formação profissional (Contabilidade e áreas afins) } \\
\hline $\begin{array}{c}\text { CNE/CES } \\
\text { no }^{0} .10 / 2004\end{array}$ & $\begin{array}{l}\text { Estudos de Formação Profissional: } \\
\text { - Estudos específicos atinentes às Teorias da Contabilidade; } \\
\text { Noções de: } \\
\text { - Atividades atuariais; } \\
\text { - Quantificações de informações financeiras, patrimoniais, governamentais/ não-governamentais; } \\
\text { - Auditoria; } \\
\text { - Perícia; } \\
\text { - Arbitragem; e } \\
\text { - Controladoria, aplicáveis tanto no setor público quanto privado. }\end{array}$ \\
\hline IFAC & $\begin{array}{l}\text { Conhecimentos de Contabilidade, Finanças e áreas afins: } \\
\text { - Contabilidade financeira e relatórios; } \\
\text { - Contabilidade gerencial; } \\
\text { - Tributação; } \\
\text { - Direito comercial; } \\
\text { - Auditoria; } \\
\text { - Finanças e gestão financeira; } \\
\text { - Ética profissional. }\end{array}$ \\
\hline AICPA & $\begin{array}{l}\text { Competências Funcionais: } \\
\text { - Modelagem de decisão: } \\
\text { - Análise de risco; } \\
\text { - Mensuração; } \\
\text { - Relatórios; } \\
\text { - Pesquisa. }\end{array}$ \\
\hline AECC & $\begin{array}{l}\text { Conhecimentos de Contabilidade e Auditoria: } \\
\text { - Conhecimento da história e do pensamento contábil; } \\
\text { - Compreensão do conteúdo, conceitos, estrutura e significado dos relatórios internos e externos; } \\
\text { - Entendimento do significado e da aplicação, bem como da metodologia dos pareceres emitidos; } \\
\text { - Habilidade de aplicar e utilizar os dados, julgar e avaliar riscos e resolver problemas reais. }\end{array}$ \\
\hline $\begin{array}{c}\text { ISAR/ } \\
\text { UNCTAD }\end{array}$ & $\begin{array}{l}\text { Conhecimentos de contabilidade e assuntos afins: } \\
\text { - Contabilidade básica; } \\
\text { - Contabilidade financeira; } \\
\text { - Relatórios gerenciais avançados; } \\
\text { - Contabilidade gerencial; } \\
\text { - Tributação básica e avançada; } \\
\text { - Sistemas de informações contábeis; } \\
\text { - Direito comercial; } \\
\text { - Fundamentos de auditoria e Auditoria avançada; } \\
\text { - Finanças e gestão financeira; } \\
\text { - Integração de Conhecimentos; } \\
\text { - Relatórios financeiros e contabilidade avançada para setores especializados; } \\
\text { - Contabilidade gerencial avançada; } \\
\text { - Gestão financeira avançada; } \\
\text { - Estágio em Contabilidade. }\end{array}$ \\
\hline \multicolumn{2}{|c|}{ Conhecimentos Administrativos e Organizacionais } \\
\hline $\begin{array}{c}\text { CNE/CES } \\
\text { no }^{0} .10 / 2004\end{array}$ & $\begin{array}{l}\text { Conteúdos de formação básica: } \\
\text { - Administração; } \\
\text { - Economia; } \\
\text { - Direito; } \\
\text { - Métodos Quantitativos; } \\
\text { - Direito; } \\
\text { - Estatística. }\end{array}$ \\
\hline
\end{tabular}




\begin{tabular}{|c|c|}
\hline IFAC & $\begin{array}{l}\text { Conhecimentos organizacionais e de negócios: } \\
\text { - Economia; } \\
\text { - Ambiente de negócios; } \\
\text { - Governança corporativa; } \\
\text { - Ética; } \\
\text { - Mercado financeiro; } \\
\text { - Métodos quantitativos; } \\
\text { - Comportamento organizacional; } \\
\text { - Tomada de decisões gerenciais e estratégicas; } \\
\text { - Marketing; e } \\
\text { - Negócios internacionais e globalização. }\end{array}$ \\
\hline AICPA & $\begin{array}{l}\text { Competências de negócios: } \\
\text { - Pensamento crítico e estratégico; } \\
\text { - Visão do setor; } \\
\text { - Perspectiva internacional e global; } \\
\text { - Administração de recursos; } \\
\text { - Perspectiva legal; } \\
\text { - Marketing / Foco no cliente. }\end{array}$ \\
\hline AECC & $\begin{array}{l}\text { Conhecimentos organizacionais e de negócios: } \\
\text { - Entendimento das forças econômicas, sociais, culturais e psicológicas que afetam a organização; } \\
\text { - Conhecimento dos processos internos da organização e capacidade de aplicá-los em situações } \\
\text { específicas; } \\
\text { - Conhecimento da maneira como as mudanças organizacionais são criadas e gerenciadas; } \\
\text { - Compreensão dos impactos da TI nas atividades da organização. }\end{array}$ \\
\hline $\begin{array}{l}\text { ISAR/ } \\
\text { UNCTAD }\end{array}$ & $\begin{array}{l}\text { Conhecimentos administrativos e organizacionais: } \\
\text { - Economia; } \\
\text { - Métodos quantitativos e estatística para administração; } \\
\text { - Políticas administrativas, estrutura organizacional básica e comportamento organizacional; } \\
\text { - Funções, práticas e operações gerenciais; e } \\
\text { - Marketing. }\end{array}$ \\
\hline \multicolumn{2}{|c|}{ Tecnologia da Informação } \\
\hline $\begin{array}{l}\text { CNE/CES } \\
\text { n }^{0} .10 / 2004\end{array}$ & $\begin{array}{l}\text { - Conhecimentos que habilitem o futuro profissional a desenvolver, analisar e implementar } \\
\text { sistemas de informações, tanto contábeis quanto gerenciais. }\end{array}$ \\
\hline IFAC & $\begin{array}{l}\text { - Grupo de conhecimentos que permitam ao profissional utilizar, avaliar, estruturar e gerenciar } \\
\text { sistemas de informações informatizados. }\end{array}$ \\
\hline AICPA & $\begin{array}{l}\text { - Conhecimento que permitem que o profissional aplique e desenvolva suas competências } \\
\text { funcionais, pessoais e de negócios. }\end{array}$ \\
\hline \multicolumn{2}{|r|}{ I } \\
\hline $\begin{array}{l}\text { ISAR/ } \\
\text { UNCTAD }\end{array}$ & $\begin{array}{l}\text { Conhecimentos de TI: } \\
\text { - Conceitos de TI para sistemas gerenciais; } \\
\text { - Controles internos em sistemas de gestão informatizados; } \\
\text { - Gestão da adoção, implementação e uso de TI e de segurança das informações; } \\
\text { - Comércio eletrônico. }\end{array}$ \\
\hline \multicolumn{2}{|c|}{ Habilidades e outros conhecimentos } \\
\hline $\begin{array}{l}\text { CNE/CES } \\
\text { n }^{0} .10 / 2004\end{array}$ & $\begin{array}{l}\text { Habilidades previstas: } \\
\text { - Visão sistêmica e interdisciplinar da atividade contábil; } \\
\text { - Capacidade de elaborar pareceres e relatórios que atendam às necessidades dos usuários; } \\
\text { - Aplicar de maneira adequada a legislação relacionada às funções contábeis; } \\
\text { - Liderar equipes multidisciplinares no processo de captação dos insumos necessários ao controle } \\
\text { técnico e à geração e disseminação de informações contábeis; } \\
\text { - Exercer suas responsabilidades demonstrando domínio das funções contábeis; } \\
\text { - Exercer com ética e proficiência as atribuições e prerrogativas prescritas através da legislação. } \\
\text { Conteúdo de formação teórico-prática: } \\
\text { - Estágio curricular supervisionado; } \\
\text { - Atividades complementares; } \\
\text { - Estudos independentes; } \\
\text { - Conteúdos optativos; } \\
\text { - Práticas em laboratório de informática, utilizando softwares atualizados para contabilidade. }\end{array}$ \\
\hline
\end{tabular}




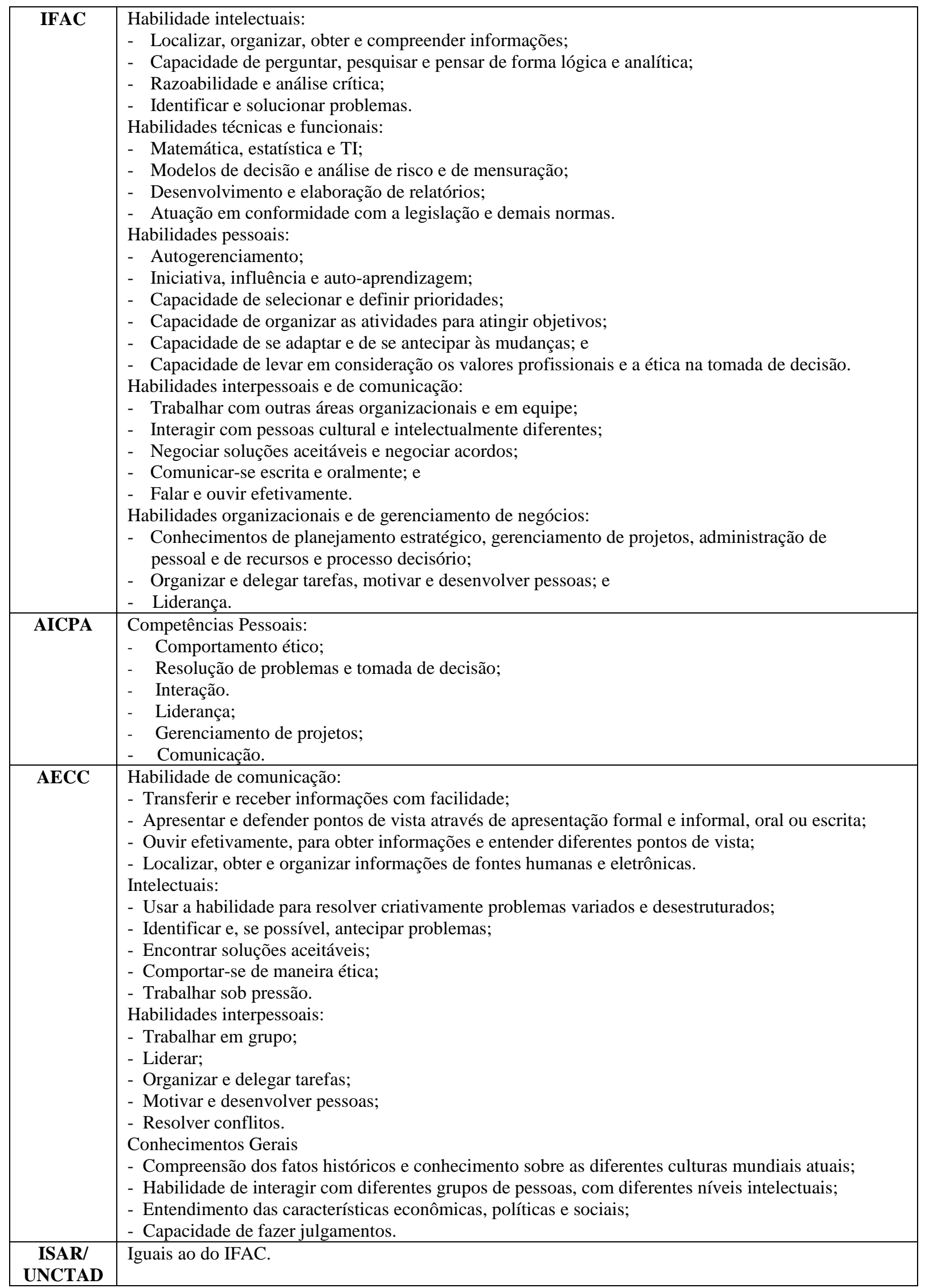

